\title{
La contribución de la Unión Europea a la gobernanza económica mundial ante la crisis del paradigma globalizador
}

\author{
Dra. Ainhoa Lasa López \\ Investigadora postdoctoral Cátedra Interuniversitaria de Derecho y Genoma Humano. \\ Universidad de Deusto-Universidad del País Vasco/EHU
}

\begin{abstract}
Sumario: I. Aproximaciones generales al estado de la cuestión: Gobernanza global vrs. Gobierno de la globalización.-II. Globalización, Unión Europea y gobernanza económica. 1. Los efectos del modelo económico de la globalización en la constitución económica del Estado social: del primado de la política a la centralidad del mercado. 2. El paradigma globalizador en el proceso de integración europeo.-_III. La gobernanza económica europea: el Tratado de Lisboa como referente normativo. 1. El gobierno débil. 2. El control fuerte. 3. El Pacto de Estabilidad y Crecimiento.- IV. Posición de la Unión Europea en el escenario de crisis de la globalización: especial referencia al papel de la Unión Europea en el G-20.- V. Consideraciones finales.
\end{abstract}

Resumen: La primera gran crisis de la globalización ha sumido a las economías del mundo en un estado de incertidumbre que requiere la adopción de decisiones eficaces para hacer frente a la misma. Lógicamente, la Unión Europea como interlocutor político en la arena mundial no puede permanecer ajena a esta situación. En el actual debate entre gobernanza global-gobierno de la globalización, las instituciones europeas han hecho valer el paradigma jurídico-político y su correspondiente modelo económico, sobre el que se construye el proyecto de integración. El Estado-mercado y su correlato de actuación económica, el Estado regulador, han estado muy presentes en los ejes de actuación propuestos por la Comisión para el establecimiento de una gobernanza económica global sólida frente a la crisis, en las Cumbres del G-20 celebradas en el 2010. Principios de actuación que también han dejado sentir sus efectos en el propio espacio europeo a través de la propuesta de reforma del Pacto de Estabilidad y Crecimiento.

Palabras clave: Estado mercado, Estado regulador, globalización económica, gobernanza económica europea y gobierno global de la economía.

Abstract: The first major crisis of globalization has left economies around the world in a state of uncertainty that requires the adoption of effective decisions to address it. Logically, the European Union as a political actor in the international arena cannot remain indifferent to this situation. In the current debate between global governance-the government of globalization, European institutions have made use of the legal-political paradigm and its corresponding economic model on which 
to build the integration project. The Market State and its correlation with economic performance, the Regulatory State, have been at the lines of action proposed by the Commission for the establishment of a strong global economic governance facing the crisis in the G-20 Summit of held in 2010. Lines of action that have also left their toll on the European space over the proposed reform of the Stability and Growth Pact.

Keywords: Market State, Regulatory State, economic globalization, European economic governance and global government of the economy.

\section{Aproximaciones generales al estado de la cuestión: Gobernanza global vrs. Gobierno de la globalización}

La primera gran crisis económica y financiera de la globalización ha puesto de relieve las carencias sociales, económicas y políticas de las que es portador el modelo jurídico político gestado a finales de los ochenta como alternativa a la forma Estado social. Una consideración que confirma su calificación de «sistémica». En otras palabras, no estamos hablando sólo de fracaso estructural del sistema financiero como si éste actuara como un sistema autónomo e independiente tanto del sistema económico, como del sistema estatal o político. Es decir, como si la crisis fuera consecuencia tan sólo de los errores o desvaríos de una de las variables del sistema, una simple anomalía del sector de las finanzas subsanable aplicando las medidas correctivas adecuadas. Parafraseando las palabras de la célebre ideóloga marxista Rosa Luxemburgo en su obra ¿Qué es la economía?: "lo más notable de esto es que todos los afectados, el conjunto de la sociedad, consideran y tratan a la crisis como algo fuera de la esfera de la voluntad y el control humanos, un golpe fuerte propinado por un poder invisible y mayor, una prueba enviada desde el cielo, parecida a una gran tormenta eléctrica, un terremoto, una inundación».

Por el contrario, esta crisis no tiene sólo una causa, sino que trae sus causas de las contradicciones de las propias condiciones de funcionamiento político, económico y jurídico del proceso globalizador. El Estado regulador como forma de actuación económica del poder público en la economía, como alternativa a una dirección política de la economía, el Estado como garante del mercado y sus prerrogativas, representan los principales rasgos de la propuesta articulada en los años ochenta en respuesta al malestar generado por la forma de Estado constitucionalizada en los textos fundamentales de la segunda postguerra mundial, el Estado social. En este punto, sería conveniente hacer siquiera un breve inciso al objeto de aclarar a grandes rasgos las diferencias existentes entre los conceptos Estado regulador y Es- 
tado mercado. Fundamentalmente, porque ambos términos constituyen los presupuestos metodológicos que hemos adoptado en la presente reflexión en aras a configurar a la globalización como el fundamento legitimador de un nuevo diseño constitucional que define una organización de la sociedad y de la política expresada por el vínculo del capital.

Por una parte, el Estado regulador representa una de las interpretaciones gestada en la década de los ochenta del siglo pasado en torno a la revisión de los mecanismos de intervención pública en la economía. El tránsito del heterogobierno del mercado y el primado de la política al Estado regulador expresa la disolución de los vínculos políticos establecidos por el modelo económico del constitucionalismo social. La autonomía del mercado es incompatible con el gobierno del mercado, y para preservar dicha autonomía es necesaria la subordinación de la política ahora dirigida a resolver las contradicciones que ha creado el Estado social al proceso de acumulación. Lo relevante del Estado regulador es que desnaturaliza los contenidos de la constitución económica del Estado social a través del progresivo desmantelamiento de los vínculos impuestos al sistema económico ${ }^{1}$.

Por otro lado, el Estado mercado como nueva forma de Estado sitúa la garantía del mercado como elemento definidor de las relaciones que se establecen entre las esferas pública y privada ${ }^{2}$. Paralelamente, la constitución económica del Estado mercado, introduce la regulación como mecanismo de tutela del mercado que se convierte en el objetivo fundamental de la intervención pública. La regulación como forma de intervención pública en la economía dirigida a garantizar la centralidad y autonomía del mercado define el modus operandi del modelo económico del Estado mercado que de acuerdo con algunas lecturas politológicas, como las ya señaladas de Antonio La Spina y Giandomenico Majone, asume la denominación de Estado regulador. De tal forma que el Estado regulador no es ninguna forma de Estado, ni representa un estadio evolutivo intermedio entre el Estado social y el Estado mercado, sino una nueva forma de intervención en la economía adscrita a la forma de Estado mercado.

Actualmente, la centralidad del vínculo económico, la definición de la intervención social por y desde el mercado, la funcionalidad del modelo social al mercado y sus condicionantes, devienen fórmulas y mecanismos ineficaces para hacer frente a los desafíos que la crisis de la globalización ha generado.

${ }^{1}$ Para un análisis más detallado ver: LA SPINA, A., MAJONE, G., Lo Stato regolatore, ed. Il Mulino, Bologna, 2000.

${ }^{2}$ BOBBIT, P. C., The shield of Achilles. War, peace and the course of history, ed. Red Classic Penguin, London, 2003. 
No obstante lo señalado, todo parece apuntar a que las prerrogativas del mercado y su garantía seguirán siendo la única premisa irrenunciable para la superación de esta crisis. Sobre todo, si se tiene en cuenta que mayoritariamente los análisis de las causas detonantes de la crisis no se circunscriben a la globalización como proyecto político, sino como hemos dicho, tan sólo a uno de sus elementos o subsistema del sistema económico globalizador, el sistema financiero. Ni siquiera aquellos planteamientos que defienden la idea de dar un aparente giro copernicano a la gobernanza global en términos de «networked minimalism» ${ }^{3}$, o que ponen el acento en la necesidad de un gobierno global de la economía con capacidad de respuesta e intervención frente a la actualmente ineficaz gobernanza económica global ${ }^{4}$, logran superar los límites del proyecto globalizador al que se circunscriben. En primer lugar, porque este minimalismo de redes está condicionado en su definición por las propias demandas de la globalización. Así, cuando se dice «de redes» porque la globalización tiene en las redes de políticas públicas a su mejor diseño estructural frente a las tradicionales políticas públicas intervencionistas del constitucionalismo social, y «de mínimos», porque la gobernanza sólo es aceptable a nivel mundial si no sustituye la gobernanza nacional y sus intrusiones en la autonomía nacional están legitimadas en términos de resultados de cooperación ${ }^{5}$, lo que en realidad se está afirmando es la necesaria protección de la dinámica globalizadora como proyecto político y no un cambio de paradigma.

En este sentido, la apelación en mayo de 2010 de Dominique StraussKahn, Director Gerente del FMI a la «creación de una moneda global emitida por un banco central global que pueda obrar en calidad de prestamista de último recurso, con una gobernanza sólida y características institucionales», supone apuntalar la panoplia instrumental de protección del vínculo económico preservándolo de perturbaciones e injerencias no tanto endógenas al propio sistema, como exógenas o imputables a futuras tentativas de reinstaurar un modelo económico inspirado en el vínculo social. La apuesta por una continuidad del modelo de gobernanza económica mundial frente a un gobierno global de la economía que incorpore la integración positiva o vínculo social no es rastreable en este planteamiento.

En segundo lugar, porque tampoco las propuestas articuladas en torno al establecimiento de un nuevo paradigma de gobierno de la globalización logran ir más allá de los propios límites que encierra el modelo, introdu-

${ }^{3}$ KEOHANE, R. O., NYE, J. S., «Introduction» en NYE. J. S., DONAHUE, J. D. (ed.), Governance in a globalizing world, ed. Brookings Press, 2000.

4 VVAA. «Una nueva gobernanza global: propuestas para el debate», Fundación Alternativas, ed. Marcial Pons, 2010, pp. 141 y ss.

5 KEOHANE, R. O., NYE, J. S., op. cit., nota 3. 
ciendo alta dosis de ambigüedad. Como alternativa a la actual globalización en crisis, se propone otra de nuevo cuño que tiene como «líneas maestras» de actuación entre otras: una cohesión social a escala mundial ${ }^{6}$, redistribución y sostenibilidad ${ }^{7}$, una reforma estructural de los organismos de Bretton Woods $^{8}$, la creación de una verdadera moneda de reserva internacional ${ }^{9}$, el reforzamiento del sistema de BPI (Bienes Públicos Internacionales) y el establecimiento de impuestos globales que generen nuevas fuentes de financiación al desarrollo ${ }^{10}$.

Ciertamente, estos planteamientos encierran aspectos claves que afectarían al diseño jurídico político de la globalización, hasta el punto de determinar la propia superación del modelo. En particular, cuando se hace referencia a la cohesión social, la sostenibilidad y la redistribución. Redistribuir interviniendo en el mercado para corregir las disfuncionalidades sociales que éste genera supone establecer un gobierno de la economía a escala mundial y por lo tanto, de acuerdo a una lógica de funcionamiento muy distinta a la propia del sistema económico globalizador. Hasta aquí, parece clara la propuesta en términos de confrontación con y superación de la lógica globalizadora a través del establecimiento y reasignación de nuevas funciones en los términos descritos.

Los problemas surgen cuando el marco teórico desde el que se definen las funciones que los Estados deben asumir es el mismo, esto es la globalización. La globalización como oportunidad, como escenario desde el que actuar los cambios, impide hablar de confrontación de modelos y sitúa el discurso en el marco de la continuidad y no de la ruptura. Nos encontramos con argumentos que tratan de conciliar los contenidos de uno y otro modelo, como si los términos de la relación gobernanza global-gobierno de la globalización pudieran conjugarse en una multiplicidad de significados llamados a complementarse entre sí. La desvinculación de la globalización de su conexión con el proceso de desmantelamiento de los postulados del constitucionalismo social como si el proceso globalizador tuviera una función permanente, una estructura capaz de adecuarse a las sucesivas crisis económicas y financieras mundiales que no comprometen sus rasgos más característicos. Un planteamiento que permite sustraerse a la confrontación entre gobernanza global y gobierno global, presentando a este último como una mera consecuencia de la evolución del sistema, pero de ninguna manera contradictorio con el mismo.

\footnotetext{
6 VVAA., op. cit., nota 4, pp. 84-87.

7 Ibid., pp. 87-91.

8 Ibid., pp. 96-98.

9 Ibid., pp. 103-104.

10 Ibid., pp. 104-108.
} 
Frente a estas reflexiones, desde nuestra propuesta cualquier análisis que se adopte en la explicación del surgimiento de la globalización conduce a afirmar desde el punto de vista del derecho constitucional, como ya hemos señalado, su naturaleza de proyecto político y, como tal, de imposición de un nuevo diseño constitucional que se define por contraste con el Estado social. Sólo desde esta perspectiva es posible aprehender las transformaciones que el nuevo modelo incorpora. Para ello tomaremos como parámetro de referencia la propia noción de gobernanza. Siguiendo la clasificación de Roderick Rhodes ${ }^{11}$, existen al menos seis acepciones distintas del término gobernanza. Desde el punto de vista del derecho constitucional, el que aquí nos interesa es el que define la gobernanza como «Estado mínimo». En palabras de Roderick, se trata de «un término general para redefinir el alcance y la manera de intervención pública y el uso de operadores económicos privados para la prestación de servicios públicos» ${ }^{12}$. Esta definición va más allá de una mera descripción analítica de los cambios experimentados en las estructuras del gobierno británico de los años ochenta que sirven al politólogo inglés de premisas para aplicar los diferentes usos de la gobernanza. Estado mínimo implica una nueva recomposición de las bases materiales del Estado social y su adaptación al contexto de la globalización a través de la imposición del nuevo paradigma. La regulación como mecanismo de intervención pública, no significa una retirada del Estado, sino de la dirección política del mercado. La gobernanza supone la implantación de una nueva estructura, el Estado regulador, frente al poder interventor del Estado social. De ahí que la afirmación de la gobernanza económica conlleve la negación del gobierno de la economía y viceversa.

En este contexto, la crisis sistémica de la globalización ha supuesto no tanto una oportunidad para reafirmar los valores de la solidaridad, la justicia social, la igualdad material, sino para consolidar los valores del paradigma económico globalizador. Una apuesta por los antedichos valores, en la que la Unión Europea (en adelante UE) ha desempeñado un papel fundamental como actor político en la esfera internacional en general y, en las cumbres del G-20 en particular.

\section{Globalización, Unión Europea y gobernanza económica}

El emergente contexto globalizador de los años ochenta representa el marco privilegiado desde el que analizar las implicaciones que aporta este proceso. De hecho, su uso generalizado para abordar las transformaciones

11 RHODES, R., «The new governance: governing without government» en Political Studies, XLIV, 1996, p. 653.

12 Ibid., pp. 653-654. 
estatales y las realizadas en el sistema económico, lo convierten en el referente por excelencia por parte de la literatura actual ${ }^{13}$.

Sin subestimar la introducción de elementos novedosos que condicionan los antiguos patrones de comportamiento de las esferas políticas y económicas, consideramos que no es tanto el análisis pormenorizado de estos elementos como la consideración del paradigma globalizador como fundamento legitimador de un nuevo diseño constitucional, lo que dota de unidad y coherencia al conjunto de la reflexión. Fundamentalmente, porque la reorganización productiva y social que acompaña al proceso globalizador no obedece a un reajuste coyuntural, sino que adopta el perfil de una forma de ruptura que menoscaba el ámbito de materialización de las trasformaciones del Estado social. La alusión a los cambios registrados en los ámbitos económico y político es ilustrativa de la transformación. La pérdida de capacidad de decisión política para intervenir en el ámbito económico implica una redefinición de la relación política-economía sobre la base de nuevos parámetros que legitiman la retirada de la política de los espacios de decisión del mercado. Este paulatino desplazamiento de las tradicionales formas de intervención estatal en los ámbitos económico y social, revela un creciente abismo entre los procesos de mercado cada vez más globales y las políticas intervencionistas de pleno empleo redefinidas en torno al nuevo paradigma de la flexibilidad ${ }^{14}$.

De esta manera, la globalización adquiere la dimensión de proyecto político que define una organización de la sociedad y de la política expresada por el vínculo capitalista. Acercarse al proceso globalizador desde este enfoque permite desvincularse del debate sobre la debilidad del Estado que sin embargo, ocupa un lugar preferente en los trabajos sobre esta cuestión. Sobre todo, porque el elemento determinante de la globalización es su estrategia de acumulación del capitalismo en la nueva fase postfordista que tiene en los Estados a sus principales protagonistas. De tal forma que el Estado desempeña un papel decisivo en la reproducción de las condiciones extraeconómicas de la acumulación para garantizar tanto las dinámicas capitalistas como su supervivencia ${ }^{15}$.

13 BRENNER, N., «Global cities, global status: global city formation and state territorial restructuring in contemporary Europe» en Review of Internacional Political Economy, n. ${ }^{\circ} 5$, 1998, pp. 1-38. SYKES, R., PALIER, B., PRIOR, P. M., Globalization and European Welfare States: challenges and change, ed. Basingstone, Palgrave, 2001. SWANK, D., Global, capital, political institutions and policy chance in developed Welfare States, ed. Cambridge University Press, 2002.

${ }_{14}$ PECK, J., THEODORE, N., «Work first: workfare and the regulation of contingent labour markets» en Cambridge Journal of Economics, n. ${ }^{\circ}$ 24, 2000, pp. 119-38.

15 BARCELlONA, P. , ¿Quale politica per il terzo millenio?, ed. Dédalo, Bari, 2000, p. 127. BRENNER, N., «De-bordering the state: new spaces in internacional relations» en New Political Science, n. ${ }^{\circ}$ 35, 1996, pp. 69-107. CERNY, P. , «Globalization and the disar- 
Por eso consideramos errónea la tesis que caracteriza a la globalización como opuesta al Estado. En nuestra opinión, el acento debe ponerse en la pérdida de control estatal en la economía como consecuencia de la autosuficiencia de las dinámicas económicas. La confrontación sólo es posible si la perspectiva de análisis se traslada a la incompatibilidad entre el proceso globalizador, entendido como estrategia de acumulación, y una determinada forma de Estado. Lo que permite a su vez situar el discurso en un plano de confrontación de modelos o si se prefiere, de formas de Estado, la que acompaña a las decisiones políticas que introduce la globalización frente a la del Estado social.

El análisis acerca del determinismo naturalista del sistema económico capitalista ha sido desmentido a través de las investigaciones efectuadas por historiadores, sociólogos y antropólogos. Las conclusiones de estos trabajos conducen a situar al mercado como el resultado final de una construcción social y política. Una de las investigaciones más concluyentes fue la realizada por Karl Polanyi en su obra la «Gran transformación», en la que como crítica al liberalismo económico demuestra que el comercio internacional no fue fruto de una espontánea evolución desde los propios mercados, sino que fue introducido políticamente a través de la hegemonía inglesa, esclareciendo el papel del Estado en su determinación. Este capitalismo institucionalizado que propone Polanyi significa que el mercado es una institución política y como tal, establece relaciones de dependencia con el Estado. De ahí que la instancia política se constituya como el centro de decisión que instaura y define las relaciones que se articulan entre el mercado y el derecho. Esta fórmula política de control del mercado que luego se materializó en la construcción del Estado social, tiene un soporte incontestable en el proceso histórico de configuración del sistema económico capitalista desde el fin del capitalismo concurrencial ${ }^{16}$.

En esta dinámica se sitúa el keynesianismo político económico del Estado social donde la autonomía en la política económica del Estado implica una respuesta favorecida por los Estados a una globalización ingobernada que se generaliza a comienzos del siglo pasado. En esta nueva disposición

ticulation of political power: towards a new middle ages?» en GOVERDE, H., CERNY, P. G., PHILIP, M., LENTNER (edit.), Power in contemporary politics. Theories, practices and globalizations, ed. Sage, London, 2000, pp. 170-86. OHMAE, K., La fine dello stato nazionale, ed. Baldwein \& Costaoldi, Milano, 1991. JESSOP, B., The future of the capitalist state, ed. Polity Press, 2002, London, pp. 210-11. Del mismo autor ver también: «State theory, regulation and autopoiesis: debates and controversies» en Capital \& Class, n. ${ }^{\circ}$ 75, otoño 2001, pp. 86-90; «Reflexiones sobre la ilógica de la globalización» en Zona Abierta, n. ${ }^{\circ}$. 92/93, 2000, pp. 95-96.

16 POLANYI, K., La gran transformación. Crítica del liberalismo económico, ed. La piqueta, Madrid, 1989, pp. 228-32 y 321-33. 
del sistema económico internacional, su configuración política en torno a lo que se ha venido a denominar «embedded liberalism» ${ }^{17} \mathrm{o}$ «liberalismo dirigido», supone una estrategia política de configuración global consistente en un régimen internacional de cambios fijos que permitía la autonomía política en la gestión de los procesos económicos nacionales, beneficiando la expansión de los Estados de bienestar europeos. Estas consideraciones también han sido recogidas en la literatura económica en la que es lugar común reconocer al sistema ideado en Bretton Woods como paradigma de la simbiosis entre el proceso de regulación controlada del sistema financiero internacional y la consolidación del papel económico del Estado a nivel interno ${ }^{18}$.

Pero es sin lugar a dudas durante el proceso de gestación de la liberalización del mercado de capitales, cuando se manifiesta con mayor intensidad el papel esencial desempeñado por las instancias estatales. Es un hecho reconocido por la literatura que aborda las complejidades de la política económica internacional, la íntima conexión de la globalización financiera con las condiciones políticas liberalizadoras creadas por los Estados. En esta tesitura podemos distinguir tres tipos de decisiones políticas básicas para las futuras liberalizaciones determinantes de la ruptura de los acuerdos de Bretton Woods ${ }^{19}$.

Previamente conviene recordar que en los acuerdos de 1944, las restrictivas disposiciones sobre las finanzas reflejaban una estructura vinculada con el keynesianismo como sistema de control político de la vida económica caracterizada por el mantenimiento del equilibrio internacional, la promoción del comercio y las finanzas a escala internacional, y la promoción de tipos de cambio estables junto con un estándar monetario común. Dispositivo que reflejaba su funcionalidad a la prioridad otorgada a la autonomía económica de la política del bienestar que se veía de esta manera desvinculada de las presiones financieras internacionales. Desde esta perspectiva se ha puesto de relieve que «el sistema monetario y financiero internacional creado después de la guerra, traspone de algún modo al ámbito internacional los principios organizativos internos de los Estados Keynesianos» ${ }^{20}$. El sistema se completaba con el Fondo Monetario Internacional (FMI) y el Banco Mundial (BM) como órganos del gobierno económico del modelo

${ }^{17}$ RUGGIE, J. G., «International regimes, transactions and change: embedded liberalism in the postward economic system» en International Organization 36 (2), 1982, pp. 379-415.

18 ADDA, J., La globalización de la economía: origen y desafíos, ed. Sequitur, Madrid, 1999, pp. 1-22.

19 KAPSTEIN, E. B., Governing the global economy: international finance and the State, ed. Harvard University Press, 1994, pp. 5-6, y 32.

${ }^{20}$ ADDA, J., op. cit., nota 17, pp. 97-98. 
que garantizan su viabilidad a través del control de los movimientos de capital, el primero, y de la supervisión del empleo de fondos en los proyectos financiados a través del mismo, el segundo.

De tal modo que «la relativa estabilidad de los tipos de cambio observada en los años cincuenta y sesenta coincide, de hecho, con una fase muy específica de la historia financiera: la del predominio de un sistema público de financiación internacional y de represión organizada de las finanzas privadas. Una fase que coincide con el apogeo del Estado de Bienestar en la mayoría de las democracias occidentales, es decir, de un sistema en el que la lógica de mercado queda ampliamente reglada por la intervención política pública en cuatro ámbitos principales: gestión coyuntural, política de la competencia y de precios, distribución de la renta y protección social» ${ }^{21}$.

Principios organizativos del sistema financiero y monetario internacional que comienzan a ser desmantelados a través de un conjunto de sucesivas acciones políticas:

1. El establecimiento a finales de los cincuenta y la consolidación en la década de los sesenta del emergente mercado de los petrodólares que constituía una válvula de escape de los controles y regulaciones financieras al permitir a los operadores bancarios funcionar con divisas distintas a las del país de origen y fuera de las fronteras de los países de origen ${ }^{22}$. La sustracción a las regulaciones determina el primer eslabón en la desvinculación de los estrictos controles de las finanzas privadas establecidos en los primeros años de la posguerra. El apoyo de los Estados Unidos e Inglaterra a la concesión de mayores márgenes de libertad al sector privado tuvo como resultado el establecimiento del euromercado de Londres. La crisis energética supuso la culminación del mercado de los petrodólares y la consolidación de un sistema de financiación ajeno a la intermediación de las instituciones internacionales que hasta ese momento se habían encargado de la promoción y ayuda de los préstamos financieros. La inestabilidad y las tensiones monetarias internacionales de la década de los setenta condujeron a la práctica eliminación de los controles al mercado de capitales en los años ochenta ${ }^{23}$.

2. El rechazo de los Estados a adoptar medidas previstas en los acuerdos de Bretton Woods que implicaran una implementación de controles más efectivos sobre los movimientos de capitales, representa

21 Ibid., p. 97.

22 Ibid., pp. 90-94.

${ }^{23}$ HELLEINER, E., States and the re-emergence of global finance. From Bretton Woods to the 1990s, ed. Cornell University Press, London, 1994, pp. 8-18. 
el punto de inflexión de la dialéctica entre el régimen de paridades fijas de los acuerdos del 44 y la liberalización de las finanzas del sector privado. Adoptar una de las dos opciones suponía en esos momentos la exclusión de la otra y viceversa. La opción entre una autonomía política monetaria o una liberalización del sector de capitales concluyó en los años noventa con el establecimiento de un mercado de capitales libre y global ${ }^{24}$.

3. La estrategia de la globalización financiera despliega sus efectos en el proceso de integración europeo y por ende, en los sistemas económicos nacionales. Los dictados de la nueva coyuntura económica internacional aceleraron el proceso de integración determinando de este modo la estrecha vinculación entre ambos procesos, el globalizador y el europeo. La nueva estrategia de acumulación consecuencia de la incapacidad de la acción política keynesiana, proporciona las bases de legitimación de las nuevas políticas públicas ${ }^{25}$.

Las políticas fiscales restrictivas centradas en el control de la inflación y en el monetarismo como elemento vertebrador de las nuevas políticas económicas, sitúan al gasto social como ámbito preferente de actuación de la disciplina presupuestaria. De tal forma que actúan como factor de erosión de la protección social. Frente a la política presupuestaria keynesiana caracterizada por el gobierno del ciclo económico a través de la intervención sobre la demanda con el objetivo prioritario del pleno empleo, el empleo de terapias deflacionarias y de enfriamiento económico junto con la coordinación de la política monetaria, son condiciones necesarias e impuestas por la globalización financiera para poder competir en el propio contexto de la globalización.

Lo que singulariza a este proceso es que los límites impuestos por la centralidad del mercado como nuevo paradigma establecido por la constitución económica de la globalización, no sólo implican el desmantelamiento de los vínculos políticos de la constitución económica del Estado social, sino que además también determinan los nuevos principios organizativos del sistema. La coordinación monetaria y las políticas económicas disciplinantes constituyen los elementos de legitimación del mercado global de la organización estatal que han sido confirmados en el espacio transnacional a través de su recepción en el Acta Única Europea y el Tratado de Maastricht, y plenamente consolidados con el Tratado de Lisboa.

${ }^{24}$ Ibid., pp. 146-168.

25 SKIDELSKY, R., «Decadencia de la política Keynesiana» en CROUCH, C., (dir.), Estado y Economía en el capitalismo contemporáneo, ed. Ministerio de Trabajo y Seguridad Social, Madrid, 1998, pp. 65-106. 
Los mercados emergen de una vida económica altamente regulada e institucionalizada en la que los mercados globales son hasta el momento los últimos seguidores de esta institución política. No en vano se habla de desregulación políticamente impuesta, consistente en la desvinculación de los mecanismos de sujeción políticos del Estado social. Nos encontramos con que la estrategia política de los Estados se centra en la búsqueda de marcos de acción de larga duración basados en compromisos institucionales a través de los cuales puedan participar en la gestión e identificación de estos procesos globales de reestructuración. El espacio económico europeo es sin duda singularmente paradigmático en relación con la caracterización de la globalización como estrategia de acumulación que define nuevos límites y nuevas oportunidades para los Estados ${ }^{26}$.

En este sentido se ha puesto de relieve que el fenómeno de la globalización se refiere no tanto al triunfo universal del capitalismo como a la emergencia de un mercado mundial autorregulado. Es decir, la confrontación se establece entre mercados autorregulados e intervención pública en la economía.

\section{Los efectos del modelo económico de la globalización en la constitución} económica del Estado social: del primado de la política a la centralidad del mercado

Ya se ha hecho referencia a que los contenidos que incorpora la estrategia globalizadora establecen una clara confrontación con los propios del Estado social y, más concretamente, con sus bases materiales.

El análisis del keynesianismo desde la perspectiva de sistema de control político de la vida económica ponía de relieve su función de legitimación y sostén del proceso de acumulación privada. Pero al mismo tiempo, permitía la introducción de la idea de pacto en la caracterización del Estado social. La estrecha sinergia establecida por el círculo virtuoso keynesiano en torno a la composición técnica del capital basada en las dinámicas del modelo fordista, y su articulación con la composición política de las clases protagonistas de la lucha por la distribución en una combinación de partidos de masas y asociaciones sindicales, presuponía una imagen dualista de la estructura productiva caracterizada por la acumulación y la integración social como bases materiales del Estado social ${ }^{27}$.

${ }^{26}$ BOYER, R., «State and Market. A new engagement for the twenty first century?» en BOYER, R., DRACHE, D. (ed.), States against markets. The limits of globalization, ed. Routledge, 1996, p. 97. JESSOP, B, op. cit., nota 15, pp. 106-118. ADDA, J., op. cit., nota 17, p. 105.

${ }^{27}$ MAESTRO BUELGA, G., La Constitución del trabajo en el Estado social, ed. Comares, Granada, 2000, pp. 147-148. 
El nivel de demanda efectiva a través del pleno empleo como variable clave de la construcción de Keynes configuraba al salario como el factor central y nexo de unión entre las dinámicas fordistas y del bienestar social. El modelo fordista de relaciones industriales implicaba un círculo virtuoso de crecimiento basado en la producción en masa, una productividad creciente basada en economías de escala, rentas crecientes que propician el consumo de masas, incremento de los beneficios debido a la plena utilización de los recursos productivos del sistema económico, aumento de las inversiones y el objetivo del pleno empleo como meta de funcionamiento del sistema. Proporcionando las bases materiales para un compromiso entre capital y trabajo presidido por las nociones claves de régimen de acumulación y relación salarial ${ }^{28}$.

Por lo tanto, fordismo y keynesianismo otorgan un nuevo papel al trabajo. Por un lado, centralidad del trabajo en el sistema político que se materializa desde el punto de vista constitucional en su reconocimiento como nuevo sujeto político y, por otro lado, en los derechos sociales como dimensión de la tutela económica del mismo. En este sentido, se reconoce una doble dimensión en el derecho al trabajo: como derecho social vinculado al pleno empleo que legitima la intervención del Estado en la economía; y el derecho al trabajo como derecho a la estabilidad en el empleo, que conforman su configuración clásica en el Estado social ${ }^{29}$.

Correlativa a esta construcción es una definición del Estado social como forma de organización política fruto del compromiso capital-trabajo que comporta un intercambio político consistente en la mejora de las condiciones de vida de las clases trabajadoras a través de la constitucionalización del trabajo y la integración de las organizaciones portadoras de sus intereses en la dinámica político-institucional, a cambio de mantener el sistema económico vigente. Compromiso cuyo rasgo más característico se traduce en una nueva relación entre el poder político y económico presidida por el vínculo social que define una constitución económica basada en el heterogobierno del mercado ${ }^{30}$.

Los caracteres señalados hasta el momento permiten poner de relieve los cambios registrados a través de esta forma de Estado y ofrecen elementos suficientes para una consideración autónoma del Estado social y su expresión jurídica. Frente al principio político liberal de separación Es-

28 BOYER, R., «Relación salarial, acumulación y crisis: 1968-1982» en Crisis económica y relaciones industriales, ed. Zero, Madrid, 1985, p. 210.

29 LASA LÓPEZ, A., «La desnaturalización del constitucionalismo social en el derecho comunitario: el derecho al trabajo como ejemplo» en Revista Vasca de Administración Pública, núm. 76, 2006, págs. 203-228.

30 DE CABO, C., La crisis del Estado social, ed. PPU, Barcelona, 1986, pp. 18-19. 
tado-Sociedad, se establecía la alternativa contraria. De manera que si la traducción en el marco constitucional de la forma de Estado social se manifestaba en una clara diferenciación en relación a la forma de Estado liberal y sus paradigmas jurídicos, en nuestra opinión, también el proceso globalizador representa el intento de legitimar un nuevo paradigma en lo que constituía el ámbito de materialización de las transformaciones del Estado social, la relación política-economía. Y, por lo tanto, desde coordenadas de superación y ruptura de principios jurídicos.

Los nuevos modelos teóricos planteados por la doctrina se establecen, como se ha señalado, en torno al Estado mercado y su forma de intervención económica, el Estado regulador. No obstante, se imponen las cautelas a la hora de analizar las propuestas teniendo en cuenta las complejidades inherentes a la nueva estrategia de acumulación. Es por ello que en el empleo de conceptos como regulación, postfordismo o Workfare state, que aparecen como funciones claves de la estrategia globalizadora, se haga precisa su consideración en directa conexión con el proceso de globalización al margen de las particularidades que resultarían de un análisis por separado de cada uno de los términos.

En primer lugar, el postfordismo como su propio nombre indica implica una ruptura con el modelo fordista de producción cuyos paradigmas son: la especialización flexible, tecnología de la información y la automatización. Por todo ello, determina una nueva composición técnica del capital de acuerdo con los condicionamientos internos del propio modelo. En segundo lugar, hablar en términos de postkeynesianismo implica un nuevo sistema de control político de la actividad económica a través de expresiones como re-regulación que acentúan la primacía de la lógica económica y la funcionalidad de la intervención pública a su expansión. En tercer lugar, Workfare state se opone a formas de intervención social vinculadas al Welfare state keynesiano, en la medida en que representa una manera opuesta de afrontar la integración del trabajo. La descripción que acompaña a cada uno de estos elementos indica su necesaria correspondencia con las nuevas formas de actuación del Estado que asignan un nuevo carácter al trabajo ${ }^{31}$.

En tercer lugar, la caracterización del trabajo como factor directamente productivo consecuencia del imperativo empresarial que subsume íntegramente la subjetividad del trabajo. «Por ello el salario, tanto el individual como el social, comenzó a ser entendido cada vez más como coste de pro-

31 MAJONE, G., LA SPINA, A., «Deregulation e privatizzazione: diferenze e convergenze» en Stato e mercato, n. ${ }^{\circ} 35,1992$, p. 249. VISSER, J., «From Keynesianism to the third way: labour relations and social policy in postwar Western Europe» en Economic and industrial democracy, n. ${ }^{\circ} 21,2000$, pp. 421-456. 
ducción internacional, y menos como una fuente de demanda nacional, y el dinero empezó a circular como divisa internacional debilitando ciertamente la gestión económica keynesiana de la demanda en el ámbito nacional. Este cambio en el principal aspecto contradictorio de la forma del dinero, está estrechamente relacionado con la tendencia de la dinámica del capital industrial a estar subordinado a la lógica de la hipermovilidad del capital financiero» ${ }^{32}$.

Así, podemos definir la globalización como la estrategia de acumulación de la nueva fase postfordista que implica la inversión de la relación caracterizadora del Estado social entre el poder político y el poder económico que garantizaba el vínculo social como elemento determinante del sistema de sujeciones impuestas por las instancias políticas, y que ahora viene establecido por la centralidad del mercado.

\section{El paradigma globalizador en el proceso de integración europea}

La estrategia de la globalización financiera deja sentir sus efectos en el espacio transnacional a través del objetivo metaconstitucional de la estabilidad económica y financiera tímidamente interiorizado por el Tratado de la Unión, reforzado por los Tratados de Maastricht y Ámsterdam y, plenamente consolidado con el Tratado de Lisboa.

La crisis económica de los setenta había puesto en evidencia la eficacia de las políticas económicas keynesianas por sus efectos perturbadores para el funcionamiento del sistema económico. La fobia anti inflacionista comienza a instalarse en el discurso de los dirigentes políticos nacionales en la esfera supranacional, mostrando de esta manera su mayor predisposición a la coordinación de la política monetaria y al empleo de terapias deflacionarias de enfriamiento económico frente a las tradicionales formas de intervención estatal en los ámbitos económico y social. Elementos fundamentales para poder competir en un contexto de globalización emergente cuyas demandas tienen reflejo en el Libro Blanco «Completing the internal market» de 1985. El apoyo incondicional de los Estados miembros a la filosofía del Acta Única así lo corrobora.

Por su parte, el Tratado de la Unión de 1992 confirma el fin del proyecto del Estado social. Con el Tratado de Maastricht se materializa la compatibilidad insostenible del constitucionalismo social con los vínculos a las políticas económicas estatales establecidos por la UEM (Unión Económica y Monetaria), es decir, «la totalidad del proyecto de la unión monetaria re-

32 JESSOP, B., op. cit., nota 15, pp. 108-109. 
presenta un ambicioso programa político, emblema del determinismo económico con respecto a la política» ${ }^{33}$.

La prioridad a la libre circulación de capitales y la estabilidad de los tipos de cambio demandaba una política monetaria coordinada. Su posterior refuerzo con el PEC (Pacto de Estabilidad y Crecimiento) aprobado por el Consejo Europeo en diciembre de 1996, materializa el impulso al proceso de liberalización económico. La disciplina macroeconómica entra en el constitucionalismo económico europeo desvinculando las políticas monetarias del cumplimiento de objetivos que expresen la intervención en la cohesión social. Sanciona la prioridad de la estabilidad macroeconómica como mecanismo de tutela del sistema económico. La garantía de la competencia y de su estabilidad como instrumentos de tutela del mercado, devienen decisiones constitucionales fundamentales ${ }^{34}$.

A estos efectos se ha señalado que después de Maastricht la constitución económica europea configura al ordenamiento jurídico de la Unión como un Estado regulador ${ }^{35}$. Sin embargo, aún siendo común en la doctrina el recurso al Estado regulador para describir las reformas gestadas a finales de la década de los ochenta en base al Libro Blanco de $1985^{36}$ y, el Informe sobre la Unión Económica y Monetaria de $1989^{37}$, las divergencias aparecen en el momento de establecer la concreta institucionalización de la actividad reguladora en la Unión Europea, el nivel de acción de las actividades reguladoras en cada uno de los espacios, nacional y europeo, así como la interacción entre ambos.

En nuestra opinión, son las reflexiones de Giandomenico Majone las que mejor se adecúan al análisis de las transformaciones experimentadas en la Unión como consecuencia del establecimiento de la UEM. En su pro-

${ }^{33}$ CROUCH, C., «Introduction: the political and institutional deficits of European monetary union» en After the Euro, ed. Oxford scholarship online monographs, 2000, p. 5.

${ }^{34}$ MAESTRO BUELGA, G., «El sistema de competencias en la constitución económica europea: Unión y Estados Miembros» en Revista de Derecho Constitucional Europeo, n. ${ }^{\circ} 6$, 2006, pp. 65-99.

35 MAJONE, G., «The European Community between social policy and social regulation» en Journal of Common Market Studies, June 31 (2), 1993, pp. 153-170. También del mismo autor ver: «The rise of the regulatory State in Europe» en MÜLLER, W.C., WRIGHT (ed.), The State in western Europe: retreat or redefinition?, ed. Frank Cass, London, 1994, pp. 77-101; Deregulation or re-regulation? Regulatory reform in Europe and in the United States, ed. Pinter, London, 1990. VOGEL, S. K., Freer markets, more rules: regulatory reform in advanced industrial countries, ed. Cornell Univesity Press, 1996.

${ }^{36}$ Completing the Internal Market: White Paper from the Commission to the European Council (Milan, 28-29 June 1985). COM(85) 310, junio de 1985.

37 Report on Economic and Monetary Union in the European Community, 12 April, 1989: http://ec.europa.eu/economy_finance/emu_history/documentation/chapter13/19890412 en235repeconommetary_a.pdf. 
puesta adopta como premisa la conexión de la constitución económica de la Unión Europea con las políticas reguladoras a las que diferencia de las no reguladoras como la redistribución de los ingresos. El paso de un Estado positivo a un Estado regulador sitúa el acento en las funciones reguladoras frente a las redistributivas o de estabilización macroeconómica ${ }^{38}$. La desvinculación en el espacio europeo de las sujeciones impuestas por el vínculo social concentra la actividad reguladora en limitar la capacidad de acción estatal como espacio de definición de sus contenidos.

En este planteamiento el Estado regulador está vinculado al contenido que por sí mismo singulariza a la función reguladora y desde el que se define el resto de componentes que a él se asocian, esto es, «la definición de competencias» ${ }^{39}$. Cuando se introducen con Maastricht las competencias vinculadas a la gestión del mercado único y a la construcción de la UEM se establece la centralidad incondicionada del mercado y su autonomía. La función reguladora del poder público europeo y estatal se traduce en la garantía del mercado y su primacía.

Paralelamente, esta europeización de las funciones estatales no implica una disolución de los Estados, sino del Estado social. El control de estas funciones desde el nivel europeo responde a evitar comportamientos que comprometan al modelo económico del Estado mercado, el Estado regulador. De ahí que los mecanismos de disciplina contemplados por las competencias vinculadas a la estabilidad macroeconómica se definan unitariamente desde el nivel europeo.

\section{La gobernanza económica europea: el Tratado de Lisboa como referente normativo}

\section{El gobierno débil}

El método de gobernanza económica establecido en el TFUE (Tratado de Funcionamiento de la Unión Europea) se define desde las coordenadas del gobierno débil y vínculos jurídicos fuertes ${ }^{40}$. Aquí es donde reside el potencial absoluto del eurosistema. La sustracción de los vínculos poten-

38 MAJONE, G., «From the positive to the regulatory state: causes and consequences of change in the mode of governance» en Journal of Public Policy, Vol. 17, n. ${ }^{\circ}$ 2, 1997, pp. 139-167.

39 MAJONE, G., Regulating Europe: problems and prospects, ed. Routledge, London, 1996, p. 65.

40 Esta propuesta teórica del «gobierno débil y el control fuerte» es obra de MAESTRO BUELGA, G., op. cit., nota 32, pp. 87-94. 
cialmente lesivos a los países miembros para el proyecto de constitución económica europea no se traduce en un instrumental en la escala europea que permita la orientación política del sistema económico, como sucedía en el Estado social. La institucionalización de la intervención pública articulada normativamente en el complejo instrumental del gobierno de la economía y determinada por el vínculo social, desaparece en el espacio europeo. Sin embargo, es en el momento de tutela de la estabilidad macroeconómica cuando se acentúa la vinculatoriedad de los mecanismos jurídicos formalizados por el Tratado. Estos pertenecen al momento del control y no al de dirección.

El instrumento fundamental contemplado por el artículo 121 del TFUE es el de las OGPE (Orientaciones generales para las políticas económicas de los Estados miembros y de la Unión). En lo que respecta a los mecanismos de intervención que permiten su realización, el Tratado no establece otro mecanismo para su actuación más que la supervisión multilateral. Las competencias en este ámbito continúan en los niveles estatales.

Sin perjuicio de este grado de intergubernamentalidad presente en el mecanismo de la supervisión multilateral que atenúa el potencial de la intervención europea, no debe olvidarse que la política económica europea tiene en la garantía de la estabilidad macroeconómica la referencia primaria de su definición. Una política vinculada a instrumentos de control fuertes tales como el BCE (Banco Central Europeo) y los Bancos Centrales Nacionales, instituciones del Estado regulador. Del mismo modo, los Estados miembros en el ejercicio de la coordinación de las políticas económicas están sujetos a una serie de principios rectores (art. 119.3 del TFUE), y deberán evitar el déficit público excesivo (art. 126 del TFUE). Y todo ello, respetando el principio de una economía de mercado abierta y de libre competencia (art. 119.1 del TFUE).

Con respecto a la política monetaria, las instituciones fundamentales se estructuran a nivel supranacional. El Tratado de Lisboa refuerza institucionalmente la obligación de la estabilidad monetaria a través del BCE y el SEBC (Sistema Europeo de Bancos Centrales). Del conjunto de disposiciones que establecen los objetivos, funciones y competencias del BCE (art. 127.2, 127.3, 127.4), emergen una serie de características que son determinantes de las peculiaridades de este instituto central en la definición e implementación de la política monetaria.

En primer lugar, el objetivo prioritario, por no decir absoluto, del SEBC es mantener la estabilidad de precios. Sin perjuicio de este objetivo, el SEBC apoyará las políticas económicas generales de la Unión con el fin de contribuir a la realización de los objetivos establecidos en el artículo 3 del TUE (Tratado de la Unión Europea). Además, a la hora de perseguir tales objetivos, el SEBC actuará con arreglo al principio de una economía de 
mercado abierta y de libre competencia, fomentando una eficiente asignación de los recursos de conformidad con los principios expuestos en el artículo 119.3 del TFUE, es decir, precios estables, finanzas públicas y condiciones monetarias sólidas y balanza de pagos estable.

Precisamente, el énfasis en la estabilidad de precios como el principio constitutivo y organizativo del sistema monetario europeo es el elemento determinante de la fisonomía que caracteriza y distingue al BCE tanto de las instituciones europeas como de los organismos de la Unión descentra$\operatorname{lizados}^{41} \mathrm{y}$, que lo define como el organismo con mayor supranacionalidad hasta el momento establecido a través del derecho de la Unión. La razón de ser del BCE es la de la estabilidad de precios, de la que derivan tanto su autonomía institucional, instrumental, personal y financiera, como los límites que establece tanto para los Estados miembros, como con relación a la Unión Europea.

La manera en la que el derecho primario europeo acentúa el principio esencial de la estabilidad de precios, confirma que la naturaleza independiente del BCE no es un fin en sí misma, sino que responde a la necesidad de asegurar los contenidos fundamentales de la constitución económica del Estado mercado. Por un lado, del gobierno de la economía de los Estados miembros vinculados al constitucionalismo social, por otro, de las posibles amenazas que el peso de la intergubernamentalidad en el conjunto del Tratado pudiera conllevar. Concretamente, se ha puesto de relieve que el particular régimen de la política monetaria europea tiene su origen en una doble desconfianza: «la desconfianza instalada a raíz de los fallos de las políticas keynesianas y de las múltiples formas de intervención del Estado social en la economía, y la recíproca desconfianza entre los países que firmaron el Tratado con diversas preferencias sobre los objetivos de política económica, que temían comportamientos oportunistas de sus socios comunitarios» ${ }^{42}$.

En congruencia con estos postulados el artículo 130 del TFUE prohíbe al BCE solicitar o aceptar instrucciones de los gobiernos de los Estados miembros o de cualquier otro órgano. Una independencia que se refleja en la estructura organizativa del BCE, ya que los miembros del BCE no son los Estados miembros de la Unión Europea, sino los bancos centrales nacionales. Este sistema está compuesto por el BCE y los bancos centrales de los Estados miembros. Además, este diseño del sistema europeo de bancos centrales y del BEC a los que se encomienda definir y ejecutar la política mo-

${ }^{41}$ ZILIOLI, C., SELMAYR, M., «The European Central Bank: an independent specialized organization of community law» en Common Market Law Review, n. ${ }^{\circ}$ 37, 2000, pp. 591-644.

42 MANTOVANI, S., «Governi e governatori» en Moneta e Credito, n. ${ }^{\circ}$ 202, Vol. 51, 1998, pp. 215-252. 
netaria (art. 127 del TFUE), permite imponer una lógica técnica vinculada al objetivo principal de la estabilidad de precios. La lógica monetarista en política económica del Estado regulador introduce una desvalorización de la dirección política en la economía que pretende imponer la autonomía del mercado.

La privación de efectos a los instrumentos de intervención estatal en el sistema económico como consecuencia de la caracterización de la estabilidad de precios como la Grundnorm del ordenamiento europeo, pone al descubierto el verdadero alcance del eurosistema. Por una parte, los precios estables y las finanzas públicas saneadas condicionan la política monetaria y, por otra, la política monetaria establece esos objetivos como prioridad cuasi absoluta. La vinculatoriedad entre ambos elementos del eurosistema se define precisamente a través de los principios rectores establecidos en artículo 119.3 del TFUE. Los precios estables, las finanzas públicas y condiciones monetarias sólidas y balanza de pagos estable, individualizan el momento del control y al mismo tiempo, manifiestan la debilidad de la conexión de la política económica con la política monetaria.

\section{El control fuerte}

De acuerdo con la perspectiva aquí analizada, la dirección macroeconómica y la política monetaria se configuran como mecanismos disciplinantes subordinados al objetivo de la estabilidad macroeconómica. En este contexto se puede destacar que la vinculación de la constitución económica europea y el ordenamiento jurídico de la Unión al Estado regulador, se manifiesta en la constitucionalización de los principios rectores que legitiman al sistema monetario europeo sobre la base del BCE, expresión del paradigma regulador.

Los elementos claves de la constitución económica de la UE (la estabilidad de precios como objetivo absoluto, la disciplina presupuestaria y el SEBC) transforman la estructura constitucional de los Estados miembros, caracterizada ahora por la adopción de los parámetros del Estado postsocial. La infiltración del paradigma de la UEM supone un cambio sin precedentes en la jerarquía de los valores normativos dentro del derecho constitucional de los Estados miembros. La extensión del efecto de la estabilidad macroeconómica a las políticas sociales y económicas unido a su impacto, provoca un cambio conceptual.

Por otra parte, la caracterización de estas piedras angulares del dispositivo del sistema monetario como principios rectores puede inducir a confusión. No obstante, en el ordenamiento jurídico europeo no se ha reproducido un debate similar al protagonizado por la doctrina en los diferentes 
Estados miembros acerca del mayor o menor carácter vinculante de las proposiciones enunciadas y ello, a pesar de que la terminología jurídica empleada para su caracterización pudiera sugerirlo. Sobre todo, si tenemos en cuenta que la expresión contenida al final del Preámbulo de la CDFUE (Carta de los derechos fundamentales de la Unión): «la Unión reconoce los derechos, libertades y principios enumerados a continuación», establece una tipología de derechos que compromete el principio de indivisibilidad (asumido por la CDFUE, en un intento de equilibrar el déficit de legitimidad de los derechos sociales en relación con los derechos de libertad, integrándolos bajo la misma calificación de fundamentales). Se trata de una fórmula ambigua que la sistemática del texto de Niza no ayuda a aclarar, pero que en todo caso compromete el estatus de fundamentales de los derechos sociales porque es precisamente esta tipología la que adopta mayoritariamente en la CDFUE la forma de principios ${ }^{43}$.

Sin embargo, la aplicación del término «principio» en el ordenamiento jurídico europeo tiene una eficacia jurídica diferente según estemos en presencia de valores económicos o sociales. Una divergencia coherente con la estructura constitucional de la UEM en el TFUE. En el ordenamiento europeo los principios rectores expresan el vínculo económico que define el aspecto de garantía y autonomía del mercado interior vinculado a la forma de Estado propia del constitucionalismo de mercado, el Estado mercado que determina la centralidad del mercado y la subordinación de las políticas sociales al mismo. Es su carácter de «Grundnorm» lo que impide el desconocimiento de tales principios, en la medida en que condicionan al conjunto de las políticas de la Unión.

Estos principios rectores actúan en el Estado mercado a un doble nivel. Por un lado, poseen una fuerza persuasiva que las lecciones de la globalización no pudieron reunir por sí mismas. Estas limitaciones legales reflejan la interiorización de un compromiso político entre los Estados miembros y la UE sin precedentes en la historia constitucional. Así, nunca antes el enaltecimiento de la estabilidad monetaria fue tal en las Constituciones nacionales hasta el punto de reinar con una supremacía absoluta. Antes del Tratado de la Unión carecía de carácter autónomo y era considerada como un meca-

43 Para un análisis más detallado de esta cuestión ver: MAESTRO BUELGA, G., «Constitución económica y derechos sociales en la Unión Europea» en CORCUERA ATIENZA, J. (coord.), La protección de los derechos fundamentales en la Unión Europea, ed. Dyckinson, Madrid, 2002, p. 138. MONDINI, A., «Equilibrio finanziario e diritti sociali: dal Trattato CE alla Carta dei diritti fondamentali dell'Unione Europea» en Rivista di diritto finanziario e scienza delle finanze, LXII, 2, 1. 2003, p. 287. SCIARRA, S., «Diritti sociali. Riflessioni sulla Carta Europea dei diritti fondamentali» en Argomenti di diritto del lavoro, n. ${ }^{\circ} 2,2001$, p. 401. 
nismo instrumental vinculado a la obtención y cumplimiento de objetivos que materializaban la intervención en la cohesión social. Ahora la política monetaria aparece como un mecanismo definido por el objetivo de la estabilidad macroeconómica y desempeña funciones de integración negativa o preservación de la autonomía del mercado.

Por otro lado, la tutela del mercado como razón de ser del eurosistema también implica que el Estado encuentre límites inderogables en la gestión del balance. El concepto de unión entre la economía y la moneda refleja la estrecha relación entre la estabilidad monetaria y la disciplina presupuestaria como condición indispensable para un crecimiento económico equilibrado en una economía social de mercado altamente competitiva, tendente al pleno empleo y al progreso social (art. 3.3 del TUE).

De acuerdo con el artículo 126 del TFUE, los Estados miembros están obligados a evitar déficits públicos excesivos. De este modo, el control del déficit público constituye la piedra angular de la unión económica, como la estabilidad de precios lo es de la unión monetaria. La Comisión es el órgano competente para la supervisión del cumplimiento de la disciplina presupuestaria a través de dos criterios de valoración cuyos valores de referencia se especifican en el Protocolo (n. ${ }^{\circ}$ 12) sobre el Procedimiento Aplicable en caso de Déficit Excesivo anejo a los Tratados. El límite es un déficit presupuestario del 3 por 100 del producto interior bruto a precios de mercado y, de un 60 por 100 en lo referente a la proporción entre la deuda pública y el producto interior bruto a precios de mercado.

Las competencias macroeconómicas de los Estados, sobre todo en el ámbito presupuestario, se limitan en aras a asegurar la viabilidad de la política monetaria única a través de una serie de normas de disciplina financiera y presupuestaria como la prohibición de la financiación monetaria de los poderes públicos por los bancos centrales nacionales (art. 123 del TFUE), la prohibición del acceso privilegiado de los poderes públicos a las entidades financieras, salvo que se trate de medidas basadas en consideraciones prudenciales (art. 124 del TFUE) y, la regla de la no corresponsabilidad financiera ni de la Unión ni de los Estados miembros (art. 125 del TFUE).

De este modo se pone de relieve el valor prescriptivo de las disposiciones del artículo 119 del TFUE que obligan a los Estados miembros y a la UE a operar conforme a los principios de estabilidad de precios y disciplina presupuestaria en el marco de una economía de mercado abierta y de libre competencia. Jurídicamente esto significa que no es posible una jerarquía constitucional de valores diversa o una diversa prescriptividad de valores del ordenamiento jurídico europeo. Configurados como características deontológicas, definen las obligaciones de deber ser de los Estados miembros de la UEM, y de la propia UEM. 


\section{El Pacto de Estabilidad y Crecimiento}

Como acabamos de ver, para la coordinación de las políticas económicas de los Estados miembros, el TFUE establece dos procedimientos de coordinación macroeconómica que consisten en una coordinación económica de las políticas económicas nacionales a través de las orientaciones generales de política económica y la supervisión multilateral de su cumplimiento (art. 121 del TFUE). Y un procedimiento de coordinación de las políticas presupuestarias de los Estados miembros dirigido a evitar los déficit públicos excesivos (art. 126 del TFUE). Este último procedimiento desarrolla el principio rector de finanzas públicas y condiciones monetarias sólidas que se transforma en mecanismo disciplinante como consecuencia del vínculo de la prohibición del déficit excesivo. Sin embargo, esto no impide el establecimiento de un margen de disposición que permite que entre en juego el ámbito de las normas de indirizzo.

De ahí la adopción de una normativa específica dirigida a reforzar la dinámica económica de la UEM a través de la garantía de la disciplina presupuestaria, como es, el PEC. El elemento esencial del PEC consiste en el fortalecimiento del procedimiento de control de los déficit públicos excesivos, y su finalidad es la de asegurar las finanzas públicas saneadas como elemento básico y esencial para avanzar en la unión monetaria dada la estricta dependencia de la garantía de la estabilidad de los precios y de la existencia de condiciones económicas capaces de fomentar el crecimiento económico, con este principio rector. La prohibición que introduce adquiere sustantividad propia en la última de las fases de la integración con la entrada en vigor de los Reglamentos n. ${ }^{\circ} 1055 / 2005^{44}$ y 1056/2005 ${ }^{45}$ que lo refuerzan, incrementando la conexión entre el procedimiento de supervisión multilateral del cumplimiento de las orientaciones generales para las políticas económicas de los Estados miembros y el procedimiento de control presupuestario.

La combinación de ambas normas de derecho secundario derivado y del artículo 126 del TFUE, divide al procedimiento de control presupuestario en dos fases. La preventiva, de supervisión de la situación presupuestaria de los gobiernos nacionales con el fin de detectar los riesgos de déficit excesivos (art. 126.3 del TFUE y Reglamento 1055/2005), y la fase represiva de los déficit excesivos existentes con la imposición de sanciones a los países

${ }^{44}$ Reglamento (CE) n 1055/2005 del Consejo, de 27 de junio de 2005, por el que se modifica el Reglamento (CE) n 1466/97 del Consejo relativo al refuerzo de la supervisión de las situaciones presupuestarias y a la supervisión y coordinación de las políticas económicas.

45 Reglamento (CE) n 1056/2005 del Consejo, de 27 de junio de 2005, por el que se modifica el Reglamento (CE) n $1467 / 97$ relativo a la aceleración y clarificación del procedimiento de déficit excesivo. 
miembros que no los remedien (art. 126. 3, 126.11 del TFUE y Reglamento 1056/2005). La fase preventiva consiste en el control efectuado por la Comisión sobre la situación presupuestaria de los Estados miembros a través de los programas de estabilidad que estos presentan con el objetivo a medio plazo de alcanzar presupuestos equilibrados o con superávit, programas que en todo caso han de respetar las OGPE.

Por su parte, la fase represiva se inicia con el incumplimiento de un Estado miembro de la disciplina presupuestaria. El poder de iniciativa en este procedimiento es de la Comisión que tras elaborar un informe en el que también se tendrá en cuenta si el déficit público supera los gastos públicos de inversión, así como todos los demás factores pertinentes, incluida la situación económica y presupuestaria a medio plazo del Estado miembro (art. 126.3 del TFUE) y previo dictamen sobre dicho informe por el Comité Económico y Financiero (art. 126.4 del TFUE), lo remite al Consejo (art. 126.5 del TFUE). Después de una valoración global de la recomendación de la Comisión y las observaciones del Estado infractor, el Consejo decidirá si existe déficit excesivo en un plazo de cuatro meses a partir de la notificación de los datos económicos de los Estados (art. 126.6 del TFUE y art. 4, apartados 2 y 3, del Reglamento (CE) no 2103/2005 del Consejo, de 12 de diciembre de 2005, por el que se modifica el Reglamento (CE) no $3605 / 93$ en lo tocante a la calidad de los datos estadísticos en el contexto del procedimiento aplicable en caso de déficit excesivo).

Si la decisión es afirmativa, el Consejo ya sin la participación del Estado infractor en las demás decisiones dirigirá recomendaciones a este último para que adopte las medidas oportunas en un plazo de seis meses como máximo y corrija su déficit excesivo en el ejercicio presupuestario siguiente (art. 126.7 y art. 3.4 del Reglamento 1056/2005). Cuando el Consejo compruebe que no se han seguido sus recomendaciones en el plazo fijado, podrá hacerlas públicas (art. 126.8 del TFUE). Además, si el Estado infractor continúa sin llevar a término las recomendaciones del Consejo, éste podrá formular una advertencia a dicho Estado para que en un plazo determinado adopte las medidas dirigidas a la reducción del déficit que el Consejo considere necesarias para poner remedio a la situación (art. 126.9 del TFUE). En tal caso, el Consejo podrá exigir al Estado infractor la presentación de informes con arreglo a un calendario específico para examinar sus esfuerzos de ajuste presupuestario (Apartado segundo del art. 126.9 del TFUE). Decisiones las de esta fase represiva que no son objeto de control jurisdiccional a través de los recursos de incumplimiento, tal y como se establece en el artículo 126.10 del TFUE.

En cualquier caso, el procedimiento podrá ser suspendido sin concurren, entre otras, las circunstancias previstas en el artículo 126.7 del TFUE, es decir, la adopción por parte del Estado miembro afectado de medidas 
en respuesta a las recomendaciones del Consejo o en respuesta a las advertencias formuladas de acuerdo con el apartado noveno del artículo 126. En todo caso, cuando el Estado que ha incurrido en una situación de déficit excesivo ha recibido la advertencia del Consejo y no ha tomado las medidas pertinentes es de aplicación el dispositivo de sanciones previstas en el artículo 126.11 del TFUE que han sido concretadas por el Reglamento 1056/2005. En concreto, las sanciones previstas por el artículo 126.11 son: la publicación por el Estado en cuestión de una información adicional que el Consejo deberá de especificar antes de la emisión de obligaciones y valores, la recomendación al BEI (Banco Europeo de Inversiones) para que reconsidere su política de préstamos respecto al Estado infractor, la obligación del Estado infractor de efectuar ante la Unión un depósito sin devengo de intereses por un importe apropiado hasta que el Consejo considere que se ha corregido el déficit excesivo y, la imposición de multas de una magnitud apropiada. A este conjunto de sanciones hay que añadir la prevista en el artículo 11 del Reglamento 1056/2005, consistente en la constitución de un depósito sin intereses cuya cuantía especifica el artículo 12 del mismo Reglamento.

No obstante, ante los acontecimientos que se han sucedido en la UE desde el estallido de la crisis financiera mundial, como son el rescate de las instituciones bancarias, la deuda griega o la burbuja inmobiliaria en determinados Estados miembros, el PEC ha adquirido un protagonismo cuasi absoluto en la supervivencia del eurosistema y, la necesidad de una reforma del PEC que incorpore mecanismo más eficaces para configurar una unión monetaria más sólida frente a una crisis, se ha convertido en una demanda perentoria. Partiendo de la premisa del «alto grado de interdependencia económica existente, particularmente en la zona del euro», el Consejo Europeo de marzo de 2010 creó el Grupo Especial sobre Gobernanza Económica. La finalidad era la de presentar las medidas necesarias con el fin de alcanzar el objetivo de un marco mejorado de resolución de la crisis y una mejor disciplina presupuestaria, explorando todas las opciones para reforzar el marco jurídico. Siguiendo estas directrices, el Grupo ha recogido en su Informe Final de octubre de 2010, una serie de propuestas articuladas en torno a cinco ejes fundamentales para hacer de la gobernanza económica y monetaria europea una gobernanza más eficaz ${ }^{46}$.

Por lo que al PEC se refiere, estas medidas son: una mayor disciplina presupuestaria y, una ampliación de la vigilancia económica a través de un nuevo mecanismo de vigilancia. El acento se traslada del déficit a la deuda

46 Informe Final del Grupo Especial sobre Gobernanza Económica, Bruselas, 21 de octubre de 2010. 15302/10. 
pública y la sostenibilidad presupuestaria. Para ello, el concepto de deuda pública debe tener un peso más determinante en el mecanismo de vigilancia presupuestaria por medio de una referencia cuantitativa adecuada y de su configuración como elemento detonante del procedimiento de déficit excesivo. «En este sentido, para poner fin al procedimiento aplicable en caso de déficit excesivo no debe bastar con que el Estado miembro haya reducido el déficit por debajo del 3\% del PIB si no ha logrado situar la deuda en una trayectoria suficientemente descendente» ${ }^{47}$. $\mathrm{Al}$ mismo tiempo, se propone el establecimiento de mayores sanciones de índole no sólo económica (obligación de constituir depósitos con intereses, aplicación de multas) sino también política (aplicación de requisitos más estrictos de notificación a la obligación de presentar informes ad hoc al Consejo, una vigilancia reforzada, la publicidad de los informes) tanto en la fase preventiva como en la represiva. Paralelamente, la exigencia de una mayor eficacia se traslada también al régimen de cumplimiento vía establecimiento de un procedimiento inverso de votación por mayoría para la adopción de medidas de imposición del cumplimiento, de tal forma que salvo que una mayoría cualificada de Estados Miembros vote en contra en el Consejo, las recomendaciones de la Comisión quedarían adoptadas. La última de las propuestas hace referencia al establecimiento de requisitos mínimos sobre los ámbitos esenciales a los que los Estados miembros tendrían que adecuarse antes de finales de $2013^{48}$.

Por otro lado, como mecanismo de refuerzo del PEC se establece un nuevo mecanismo de vigilancia macroeconómica basado en un número limitado de indicadores para detectar la existencia o siquiera posible aparición de desequilibrios excesivos. Este mecanismo debería instrumentarse de modo que se garantice la coherencia con la vigilancia de las políticas presupuestarias, las reformas estructurales orientadas a impulsar el crecimiento y la estabilidad macroeconómica, y que se eviten superposiciones y repeticiones innecesarias ${ }^{49}$.

Lo relevante de esta propuesta de reforma del PEC es por una parte, que aunque pretende introducir mecanismos más estrictos frente a la aparente filosofía desflexibilizadora de la reforma del 2005, no hace sino consolidar un tipo de intervención que vincula la estabilidad macroeconómica con la autonomía del mercado. Sin en la reforma del 2005 se buscaba mantener una formulación flexible de los estrictos mecanismos procedimentales a través de disposiciones con una densidad normativa suficiente para establecer mayores márgenes a la discrecionalidad, manteniendo inalterables los límites para el déficit y la deuda y, el plazo para la corrección de los déficits, en

\footnotetext{
47 Ibid., p. 8.

48 Ibid., pp. 9-14.

49 Ibid., p. 15.
} 
la propuesta reformadora del 2010, la filosofía que acompaña al PEC es la de fortalecer los elementos de actuación en base a la prevención, la vigilancia y la aplicación de medidas correctoras.

Por otro lado, la subsunción del déficit en la deuda pública que se convierte en criterio referencial de la propuesta no significa empero, una redefinición de la estructura macroeconómica teórica e ideológica que sirve como respaldo normativo de estas reglas de control de la deuda pública y la sostenibilidad presupuestaria. Los mecanismos de control de la política de la Unión, estabilidad de precios y disciplina presupuestaria en el contexto de una economía de mercado abierta y de libre competencia, reflejan la compatibilidad de una intervención pública basada en una política monetaria de contención de la deuda pública y la centralidad de la protección del mercado. El PEC como instrumento de control y extensión de los contenidos de la constitución económica europea a los Estados miembros a través de los vínculos presupuestarios que afectan fundamentalmente a los mecanismos de intervención social nacionales (reducción del gasto social en sanidad, educación, prestaciones sociales, etc...), desempeña funciones adicionales de consolidación del modelo económico del Estado mercado.

\section{Posición de la Unión Europea en el escenario de crisis de la globalización: especial referencia al papel de la Unión Europea en el G-20}

La Comisión Europea ejerce un papel destacado en el escenario económico y financiero mundial a través de su participación en numerosos foros e instituciones internacionales. En lo que aquí interesa, quisiéramos destacar la función de la Comisión en el G-20. Sobre todo, porque en este foro se ha debatido y se debate sobre la cuestión de la gobernanza económica a nivel mundial, con lo cual, es un banco de pruebas de gran interés para analizar la posición adoptada por la Comisión con relación a esta cuestión. Lógicamente, la Comisión se erige como representante de los intereses económicos de la Unión, y por ello, del modelo económico del que es portador el proyecto.

De hecho, en la Cumbre del G-20 en Toronto en junio de 2010 se ha asistido a un interesante debate sobre el paradigma económico a adoptar para hacer frente a la crisis. La tensión entre las propuestas americanas y europeas ha quedado reflejada en la Declaración de la Cumbre de Toronto del G-20, 26-27 de junio de 2010. Frente a los planteamientos del gobierno de Obama, con una clara apuesta por estimular el crecimiento de la economía vía gasto público, heredera de la filosofía keynesiana: «Es esencial reforzar la recuperación. Para mantenerla, hemos de seguir aplicando los pla- 
nes de estímulo aprobados, mientras creamos las condiciones necesarias para que haya una demanda privada fuerte» ${ }^{50}$; los presidentes del Consejo y de la Comisión Europea, Van Rompuy y Barroso, abogaron por la reducción de la deuda pública y la sostenibilidad presupuestaria como principios fundamentales del Estado mercado: «Al mismo tiempo, los acontecimientos más recientes demuestran la importancia de garantizar la sostenibilidad de las finanzas públicas y la necesidad de que nuestros países adopten planes de sostenibilidad presupuestaria que gocen de credibilidad, estén debidamente dosificados y propicien el crecimiento de manera diferenciada y adaptada a las circunstancias de cada país $»^{51}$. Además, esta reducción del gasto público debe ir acompañada de reformas estructurales para estimular el crecimiento. Fundamentalmente, reformas sociales como las del mercado de trabajo y las pensiones.

Desde esta óptica, la recuperación pasa por adoptar bien los parámetros de un new deal rooselvetiano de nuevo cuño, adaptado a las circunstancias de la crisis económica mundial, o bien los postulados de un Estado mercado para el que la primacía de los valores económicos es incuestionable. El dilema Keynes vrs. Estado regulador, resume las coordenadas ideológicas presentes en la Cumbre que finalmente se ha saldado con una clara convergencia con las tesis europeas. Cuando en el Marco para un Crecimiento Fuerte, Sostenible y Equilibrado se reconoce el riesgo «de que un ajuste fiscal sincronizado en varias de las principales economías pueda afectar adversamente la recuperación», a renglón seguido se equipara ese riesgo con el riesgo que implica «minar la confianza y afectar al crecimiento, en caso de no adoptar procesos de consolidación fiscal donde sean precisos». En este sentido, el ajuste presupuestario se convierte en la línea de actuación preferente. Un enfoque reforzado en la Cumbre de Seúl en Noviembre de 2010. A tenor del comunicado de la Comisión sobre la valoración de los acuerdos alcanzados en la misma, destaca que en el compromiso de los miembros del G-20 de reducir los desequilibrios excesivos, y de mantener los desequilibrios en cuenta corriente en niveles sostenibles, la política de la UE en la materia representa una fuente de inspiración $»^{52}$.

Sin perjuicio de lo señalado, lo que en nuestra opinión hay que destacar es que la contribución de la Unión a la gobernanza económica global para

50 Declaración de la Cumbre de Toronto del G-20: www.elpais.com/elpaismedia/.../28/.../ 20100628elpepueco_1_Pes_PDF.pdf, p. 1 (última consulta 15/03/2011).

51 Ibid., p. 1.

52 Joint statement by President of the European Council Herman VAN ROMPUY and President of the European Commission José Manuel BARROSO at the end of the G20 Summit in Seoul. Seoul, 12 November 2010. PCE 260/10: http://www.consilium.europa.eu/ uedocs/cms_data/docs/pressdata/en/ec/117697.pdf (última consulta 15/03/2011). 
la gestión de la crisis económica mundial, pasa indefectiblemente por una defensa a ultranza del modelo jurídico-político ya presente en los Tratados Constitutivos de las Comunidades Europeas. Un modelo que la propia crisis ha cuestionado y que sin embargo, se pretende dejar intacto en sus presupuestos más prístinos. El Estado mercado emerge como el proyecto jurídico-político vencedor de la crisis. La deriva antisocial, o en otras palabras, la configuración de la dimensión social de la globalización bajo el prisma del mercado, no deja margen ni siquiera para la consideración de una gobernanza social global en igualdad de condiciones con la gobernanza económica. Una orientación en sintonía con la caracterización de la globalización como proceso de deconstrucción del constitucionalismo social.

\section{Consideraciones finales}

1. El conjunto de transformaciones experimentadas desde la década de los ochenta del siglo pasado identificaba a la nueva estrategia de acumulación del proyecto político globalizador con una nueva forma de intervención cuya característica fundamental es la de confrontarse con el Estado social. La ruptura del vínculo político por el mercado resume el fundamento legitimador que encierra la decisión política que introduce el nuevo paradigma para las nuevas políticas públicas.

2. En este contexto, el proceso de integración europea se presenta como paradigmático de la nueva estrategia de acumulación porque el proyecto de construcción del originario mercado común incorporaba una forma de intervención opuesta al modelo económico generalizado tras la constitucionalización del Estado social. Instrumentos vinculados al gobierno y a la intervención socio-económica del constitucionalismo social, frente a la garantía de la autonomía del mercado del Estado mercado y su modelo económico, el Estado regulador, a través de las libertades económicas y la competencia del espacio europeo. Este modelo económico adscrito al Estado mercado se consolida plenamente con la introducción con Maastricht de competencias vinculadas a la gestión del mercado interior y la construcción de la Unión Económica y Monetaria. La centralidad incondicionada del mercado y su autonomía, la garantía del vínculo económico y su primacía definen a la nueva forma de intervención en la que los nuevos espacios abiertos a la competencia de las instituciones de la Unión se dirigen a garantizar el sistema institucionalizado en la Unión Europea, el mercado interior y la Unión Económica y Monetaria. Nuevo modelo de intervención que teniendo a la autonomía del mercado como criterio material de delimitación de las competencias, se caracteriza por una intervención débil europea y una intervención estatal disciplinada por los mecanismos de control establecidos en el 
ámbito europeo. Gobierno débil y control fuerte resumen el método de gobernanza del Tratado de Funcionamiento de la Unión Europea.

3. La primera crisis de la globalización ha puesto en entredicho esta estrategia de acumulación vinculada al Estado mercado y su paradigma económico, el Estado regulador. Una crisis que además adquiere la dimensión de sistémica afectando al diseño material del modelo, lo que compromete sus postulados más prístinos. No obstante, las soluciones a la crisis no han ido más allá de los límites que establece el propio modelo. Cualquier propuesta o reflexión teórica que se aleje del imperativo del constitucionalismo de mercado parece abocada al rechazo o cuanto menos a su cuestionamiento en términos de viabilidad en la práctica. La supervivencia del sistema globalizador obliga a realizar la reflexión desde el propio modelo de la globalización, lo que cuestiona cualquier atisbo de avance en la consecución de un gobierno global de la economía por mínimo o residual que éste sea. Ni mucho menos, una integración positiva o social a escala global. Los intentos por avanzar hacia una dimensión social en la dinámica globalizadora terminan por subsumir a los valores sociales en la perspectiva del primado del mercado. Su carácter marginal materializado en las reflexiones de «networked minimalism», o su vinculación al siempre recurrente enunciado de la gobernanza global, los aleja de un planteamiento de confrontación con el modelo globalizador para terminar siendo reconducidos a los postulados inherentes a la estrategia de acumulación del capital.

4. En este marco, la Unión Europea receptora en sus bases constitutivas del diseño político de la globalización, no sólo se adhiere a su defensa a ultranza en el propio espacio transnacional reforzando la panoplia instrumental del Estado mercado y su constitución económica en el último referente normativo, el Tratado de Lisboa, sino que actúa como adalid de sus virtudes en la arena internacional. La participación de la Comisión en distintos foros y cumbres internacionales es sin duda el mejor indicador de la puesta en escena por parte de esta institución de la Unión, de las bondades de los principios fundamentales del Estado mercado que hace ya más de medio siglo empezaron a interiorizar los Tratados fundadores de las Comunidades Europeas. 